\section{(2) \\ BRAZILIAN JOURNAL \\ OF MEDICAL AND BIOLOGICAL RESEARCH}

www.bjournal.com.br
ISSN 1414-431X

Volume 45 (11) 995-1101 November 2012

BIOMEDICAL SCIENCES

AND

CLINICAL INVESTIGATION

Braz J Med Biol Res, November 2012, Volume 45(11) 1060-1065

doi: 10.1590/S0100-879X2012007500119

Anticonvulsant and antiarrhythmic effects of nifedipine in rats prone to audiogenic seizures

D.D. Damasceno, A.J. Ferreira, M.C. Doretto and A.P. Almeida

The Brazilian Journal of Medical and Biological Research is partially financed by

\section{Q QNPPq}

Ministério

da Ciência e Tecnologia

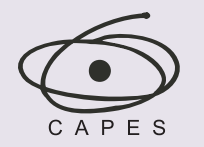

Ministério da Educação

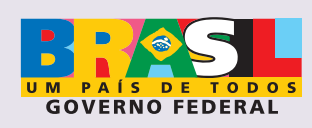

DTFAPESP

Institutional Sponsors

๑ SHIMADZU UNICAMP

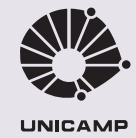

1 D. Associaçäo Explore High - Performance MS AIT $\begin{gathered}\text { de Incentivo } \\ \text { a Pesquisa }\end{gathered}$

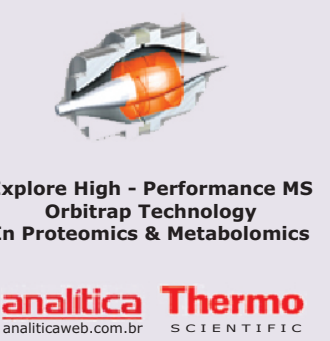

$\underset{\text { analitica }}{\text { analiticaweb.com.br }}$ Thermo
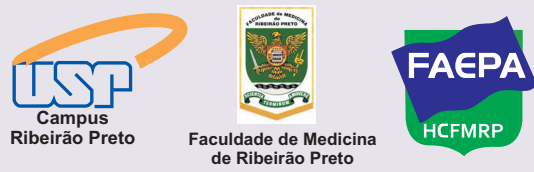


\title{
Anticonvulsant and antiarrhythmic effects of nifedipine in rats prone to audiogenic seizures
}

\author{
D.D. Damasceno ${ }^{1,2}$, A.J. Ferreira ${ }^{3}$, M.C. Doretto ${ }^{2}$ and A.P. Almeida ${ }^{2}$ \\ ${ }^{1}$ Departamento de Desenvolvimento Educacional, Instituto Federal de Educação, \\ Ciência e Tecnologia do Sudeste de Minas Gerais, Barbacena, MG, Brasil \\ 2Departamento de Fisiologia e Biofísica, Instituto de Ciências Biológicas, \\ Universidade Federal de Minas Gerais, Belo Horizonte, MG, Brasil \\ ${ }^{3}$ Departamento de Morfologia, Instituto de Ciências Biológicas, \\ Universidade Federal de Minas Gerais, Belo Horizonte, MG, Brasil
}

\begin{abstract}
Calcium ion participates in the regulation of neural transmission and the presynaptic release of neurotransmitters. It is also involved in epileptic events, cardiac arrhythmias and abnormal conduction of stimuli. The purpose of the present study was to evaluate the effects of nifedipine, a calcium channel blocker, on epileptic seizures and on reperfusion arrhythmias in rats prone to audiogenic epileptic seizures (Wistar audiogenic rats, WAR) and in normal Wistar rats ( $N=6 / g r o u p)$. The seizure severity index was applied after an intraperitoneal injection of 20 or $40 \mathrm{mg} / \mathrm{kg}$ nifedipine (N20 and N40 groups, respectively). The Langendorff technique was used to analyze cardiac function, as well as the incidence and severity of the reperfusion arrhythmias after ligature and release of the left coronary artery in rats treated or not with nifedipine. We found that nifedipine treatment decreased seizure severity $(0.94 \pm 0.02$ for WAR; $0.70 \pm 0.10$ for WAR + N20; $0.47 \pm 0.08$ for WAR + N40) and increased the latent period (13 $\pm 2 \mathrm{~s}$ for WAR; $35 \pm 10 \mathrm{~s}$ for WAR + N20; $48 \pm 7 \mathrm{~s}$ for WAR + N40) for the development of seizures in WAR. Furthermore, the incidence and severity of the reperfusion arrhythmias were lower in WAR and normal Wistar rats injected with nifedipine. In WAR, these effects were mediated, at least in part, by a decrease in heart rate. Thus, our results indicate that nifedipine may be considered to be a potential adjuvant drug for epilepsy treatment, especially in those cases associated with cardiac rhythm abnormalities.
\end{abstract}

Key words: Nifedipine; Calcium channel antagonism; Audiogenic seizures; Epilepsy; Arrhythmias

\section{Introduction}

Epilepsy is a serious neurological condition characterized by recurrent unprovoked seizures that affects approximately 60 million people worldwide (1). The mortality among patients with epilepsy is on average 2-3 times higher than that among the general population (2). The underlying mechanisms that lead to death are unclear. Several different mechanisms may be involved and there may be no single explanation for all cases. Among the various potential causes are: cerebrogenic cardiac arrhythmias, autonomic dysfunction and pulmonary edema induced by seizures (3).

Cardiac rhythm and conduction abnormalities are common during seizures, particularly if they are prolonged or generalized (4). Neurogenic cardiac arrhythmias reported during epileptic seizures comprise supraventricular tachycardia, bundle branch block, atrioventricular nodal escape rhythm (5), sinus arrhythmia, and atrial and ventricular premature depolarizations (4). Electrocardiogram (ECG) abnormalities with potentially serious alterations including ST-depression and T-wave inversion were observed in patients during the ictal and postictal period, suggesting that myocardial ischemia associated with ictal sympathetic storms may lead to lethal arrhythmias (4-6). The seizures can result in scarring as a consequence of an ischemia/ reperfusion injury and the myocardial lesions are probably related to activation of sympathetic mechanisms in the brain stem (7)

The association between myocardium reperfusion inducing abrupt increases in peak calcium and the occurrence of ventricular tachycardia and/or fibrillation suggests that intracellular calcium transients may have a significant role in initiating cardiac arrhythmias (8). Also, calcium channel

Correspondence: D.D. Damasceno, Departamento de Desenvolvimento Educacional, Av. Monsenhor José Augusto, 224, $36205-018$ Barbacena, MG, Brasil. E-mail: denis.damasceno@ifsudestemg.edu.br

Received November 13, 2011. Accepted May 24, 2012. Available online July 20, 2012. Published October 5, 2012. 
activity and enhancement of the L-type $\mathrm{Ca}^{2+}$ current are important determinants of the duration of the cardiac action potential. Therefore, increases in $\mathrm{Ca}^{2+}$ currents may potentially lead to the development of arrhythmias by triggering early after depolarization and/or causing dispersion of repolarization and reentry (9).

Some forms of epilepsy can be caused by alterations in plasma membrane $\mathrm{Ca}^{2+}$ channels (10). Furthermore, long-lasting changes in the regulation of $\mathrm{Ca}^{2+}$ currents may contribute to the persistent neuroplasticity alterations associated with epilepsy (11). Thus, as calcium and calciumdependent systems have been implicated in the induction of epilepsy, as well as in the development of arrhythmias, we investigated the effects of nifedipine, a calcium channel blocker, on the severity of seizures and on reperfusion arrhythmias in rats prone to audiogenic epileptic seizures (Wistar audiogenic rats, WAR) and in normal Wistar rats.

\section{Material and Methods}

\section{Animals}

The experiments were performed on male Wistar rats (250-300 g; 8-9 weeks of age; $N=18$ ) from the main breeding stock of Instituto de Ciências Biológicas, Universidade Federal de Minas Gerais (ICB, UFMG, Brazil) and on WAR (250-300 g; 10-11 weeks; $N=18$ ) from the inbred colony maintained in the Department of Physiology and Biophysics (ICB, UFMG, Brazil). The animals were housed individually in plastic cages under controlled lighting conditions (lights on at 6:00 am and off at 8:00 pm), room temperature at $24^{\circ} \mathrm{C}$ and with food and water ad libitum. All efforts were made to avoid any unnecessary distress to the animals and all animal procedures were performed in accordance with institutional guidelines approved by the Ethics Committee in Animal Experimentation of Universidade Federal de Minas Gerais, Brazil (CETEA-UFMG), which are in accordance with the National Institutes of Health $(\mathrm{NIH})$ Guidelines for the Care and Use of Laboratory Animals.

\section{Acoustic stimulation and behavioral evaluation of seizure severity}

The apparatus used to induce acoustic stimulation consisted of a cylindrical transparent cage inside a larger, soundproof box, provided with a door and frontal glass window for observation. A sound stimulus (120 dB SPL) was delivered into the acoustic chamber through a loudspeaker until tonic seizures appeared or during a maximum period of $1 \mathrm{~min}$. Behavior was assessed by direct observation using a set of discrete behavioral categories and quantified by means of a severity index (SI) scale ranging from zero to one (12). All animals were submitted to a screening procedure (at 70, 74, and 78 days of age) in order to determine seizure severity and to evaluate audiogenic susceptibility. The WAR display epileptic behavior after sound stimulation, presenting running fits, jumping and atonic falling, followed by tonic-clonic seizures and clonic spasms. The tests were always conducted after 4:00 pm and all seizures were induced since these animals do not have spontaneous seizures (13). A resting period of at least one week after screening was allowed before the initiation of the experimental protocols. The most frequent behavioral sequences produce the following SI values: $0.11=$ wild running with only one running fit; 0.23 = wild running with only one running fit, jumping and atonic falling; $0.38=$ wild running with two running fits, jumping and atonic falling; $0.61=$ all of the above plus tonic convulsion (back arching tonus); $0.73=$ all of the above plus partial (only forelimb or hindlimb) and generalized (forelimb and hindlimb) clonic seizures; 0.85 = all the above plus clonic spasms; $0.90=$ all of the above plus ventral flexion of the head; $0.95=$ all of the above plus forelimb hyperextension; 1.0 = all of the above plus forelimb and hindlimb hyperextension (14). Animals with $\mathrm{SI}>0.85$ were included in the experiments.

\section{Isolated heart preparation and induction of reperfusion arrhythmias}

The rats were decapitated 10 to $15 \mathrm{~min}$ after intraperitoneal injection of $400 \mathrm{IU}$ heparin. The thorax was opened, the heart was rapidly excised and immediately cooled in iced buffer and perfused through an aortic stump with Krebs-Ringer solution (KRS) containing: $118.4 \mathrm{mM} \mathrm{NaCl}$, $4.7 \mathrm{mM} \mathrm{KCl}, 1.2 \mathrm{mM} \mathrm{KH}_{2} \mathrm{PO}_{4}, 1.2 \mathrm{mM} \mathrm{MgSO} 4 \cdot 7 \mathrm{H}_{2} \mathrm{O}$, $2.5 \mathrm{mM} \mathrm{CaCl} 2 \cdot 2 \mathrm{H}_{2} \mathrm{O}, 11.7 \mathrm{mM}$ glucose, and $26.5 \mathrm{mM}$ $\mathrm{NaHCO}_{3}$. The high glucose concentration was employed to overcome possible reductions in glucose uptake by cardiomyocytes (15). The perfusion fluid was maintained at 37 $\pm 1^{\circ} \mathrm{C}$ with constant pressure $(75 \mathrm{mmHg})$ and oxygenation $\left(5 \% \mathrm{CO}_{2} / 95 \% \mathrm{O}_{2}\right)$. A force transducer (model FT3, Grass Instruments Co., USA) was attached through a heart clip to the apex of the ventricles to record the contractile force (tension, g) in a computer using a data acquisition system (Biopac System, Inc., USA). Electrical activity was recorded utilizing an ECG with two platinum electrodes placed directly on the surface of the right atrium and left ventricle (bipolar lead). A diastolic tension of $1.0 \pm 0.2 \mathrm{~g}$ was applied to the hearts (16). We also evaluated the tension developed by the hearts by calculating the derivatives $( \pm d T / d t)$ using the Acknowledge software version 3.5.7 (Biopac System, Inc.). Maximum dT/dt is a reasonable index of the initial velocity of myocardial contraction and minimum $\mathrm{dT} / \mathrm{dt}$ with myocardial relaxation. The coronary flow was measured by collecting the perfusate over a period of $1 \mathrm{~min}$ at regular intervals.

The hearts were perfused with KRS for an initial 30min period under sinusal rhythm. At the end of this time, a ligature was placed around the left anterior descending coronary artery close to its origin. Both ends of the ligature were passed through a small plastic cylinder, which was then pressed against the artery. The resulting arterial occlusion was maintained for $15 \mathrm{~min}$ by clamping the plastic cylinder and ligature. After the 15-min period of coronary 
occlusion, we reperfused the artery by removing the clamp and the tube. Reperfusion rhythm disturbances were then monitored for $30 \mathrm{~min}$ (17). Cardiac arrhythmias were defined as the presence of ventricular tachycardia (VT) and/or ventricular fibrillation (VF) after the ligature of the left anterior descending coronary artery was released. The duration of the arrhythmias was expressed in minutes, with a 30-min arrhythmia being considered irreversible (18).

\section{Experimental protocols}

The WAR were pretreated with a single dose of 20 or 40 $\mathrm{mg} / \mathrm{kg}$ nifedipine, ip (N20 and N40 groups, respectively) $1 \mathrm{~h}$ before the acoustic stimulation and behavioral evaluation of seizure severity. The animals were then decapitated and the hearts were isolated. In addition, the hearts of Wistar rats pretreated $1 \mathrm{~h}$ before the experiments with a single dose of nifedipine (20 or $40 \mathrm{mg} / \mathrm{kg}$ ) were also isolated. Control animals (Wistar and WAR) did not receive nifedipine.

\section{Statistical analysis}

Data are reported as means \pm SEM. Statistical differences were determined by the Kruskal-Wallis test followed by the Dunn post-test or one-way ANOVA followed by the Newman-Keuls post-test. $P<0.05$ was considered to be statistically significant.

\section{Results}

Administration of nifedipine caused a dose-dependent decrease in the seizure severity index in WAR (Figure 1). At the dose of $40 \mathrm{mg} / \mathrm{kg}$, nifedipine induced a significant reduction in the seizure severity index compared to untreated animals. Two of the 6 animals treated with $20 \mathrm{mg} / \mathrm{kg}$ nifedipine and 4 of the 6 rats treated with $40 \mathrm{mg} / \mathrm{kg}$ nifedipine did not present clonic or tonic convulsion while all control WAR showed these neurological reactions. Additionally, an increase in the latent period for the development of seizures was also noted in WAR treated with both doses of nifedipine (data not shown).

Under basal conditions, nifedipine administration elicited a dose-dependent decrease in the heart rate of isolated hearts of WAR and Wistar rats compared to untreated animals (Figure 2). No significant changes in systolic tension, coronary flow or maximal $(+\mathrm{dT} / \mathrm{dt})$ and minimal $(-\mathrm{dT} /$ $\mathrm{dt}$ ) contractility were observed among any of the groups (Table 1). Myocardial ischemia induced a similar reduction of approximately $50 \%$ in the coronary flow of all groups, which was sustained throughout the ischemic period. During reperfusion, cardiac arrhythmias (VT and/or VF) were observed in all groups. However, the duration of the arrhythmias was significantly decreased after nifedipine administration (40 mg/kg: $10.8 \pm 6 \mathrm{~min}, \mathrm{~N}=6$, Figure $3 \mathrm{~B}$ )

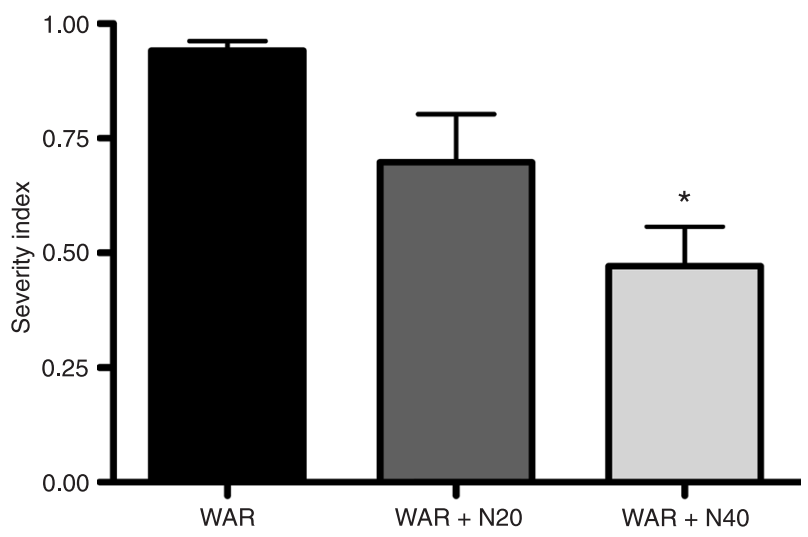

Figure 1. Severity index of seizures in Wistar audiogenic rats (WAR) treated or not with 20 or $40 \mathrm{mg} / \mathrm{kg}$ nifedipine (N20 or N40). Data are reported as means \pm SEM for 6 rats per group. ${ }^{*} \mathrm{P}<0.05$ compared to untreated animals (WAR) (Kruskal-Wallis test followed by the Dunn post-test).
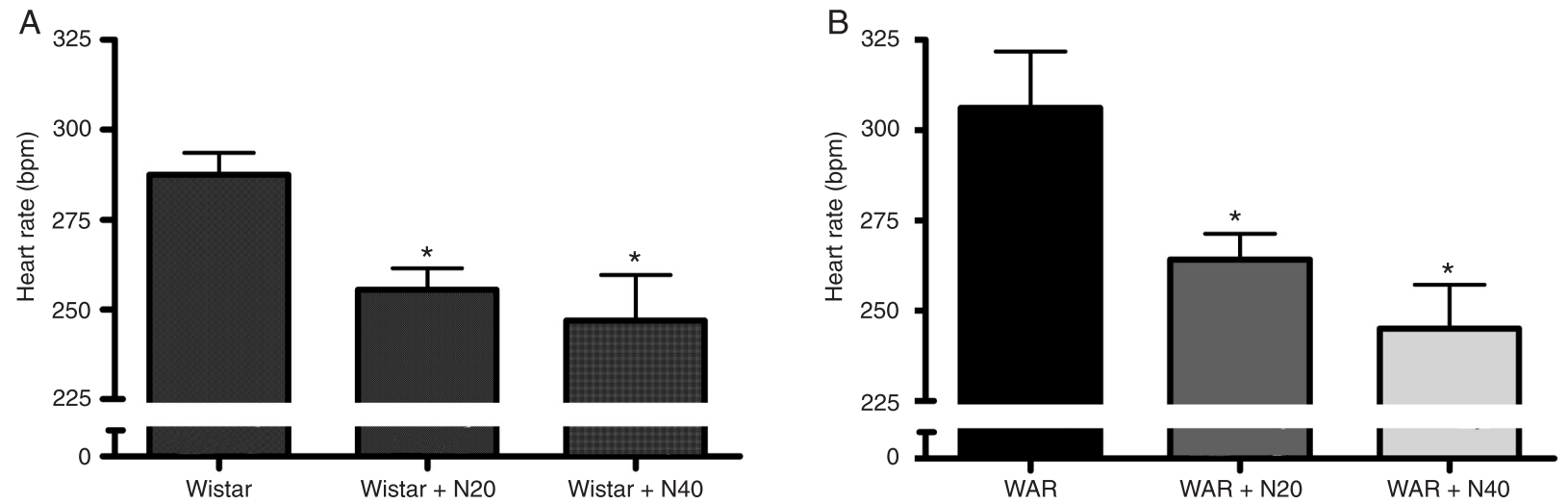

Figure 2. Effects of 20 and $40 \mathrm{mg} / \mathrm{kg}$ nifedipine (N20 and N40) on the heart rate of isolated hearts of $A$, Wistar rats and $B$, Wistar audiogenic rats (WAR). Data are reported as means \pm SEM for 6 rats per group. ${ }^{*} P<0.05$ compared to control (Wistar or WAR) (one-way ANOVA followed by the Newman-Keuls post-test). 
Table 1. Effects of nifedipine on systolic tension, coronary flow and maximal $(+d T / d t)$ and minimal $(-\mathrm{dT} / \mathrm{dt})$ contractility of isolated rat hearts from Wistar audiogenic rats and Wistar rats.

\begin{tabular}{lcccccc}
\hline & WAR & WAR + N20 & WAR + N40 & Wistar & Wistar + N20 & Wistar + N40 \\
\hline ST & $10.0 \pm 0.6$ & $9.7 \pm 1.1$ & $8.5 \pm 0.8$ & $9.5 \pm 0.6$ & $9.1 \pm 0.6$ & $8.8 \pm 0.9$ \\
CF & $7.89 \pm 0.9$ & $7.96 \pm 0.5$ & $7.11 \pm 1.0$ & $8.64 \pm 0.8$ & $8.50 \pm 0.5$ & $8.21 \pm 0.6$ \\
$+\mathrm{dT} / \mathrm{dt}$ & $211 \pm 15$ & $196 \pm 22$ & $212 \pm 19$ & $192 \pm 18$ & $182 \pm 12$ & $173 \pm 10$ \\
$\mathrm{-dT} / \mathrm{dt}$ & $231 \pm 18$ & $244 \pm 24$ & $204 \pm 18$ & $205 \pm 16$ & $202 \pm 20$ & $197 \pm 7$ \\
\hline
\end{tabular}

Data are reported as means \pm SEM for 6 rats per group. No significant differences were observed among any of the groups. $\mathrm{N} 20$ and $\mathrm{N} 40=20$ and $40 \mathrm{mg} / \mathrm{kg}$ nifedipine, respectively; $\mathrm{ST}=$ systolic tension $(\mathrm{g}) ; \mathrm{CF}=$ coronary flow $(\mathrm{mL} / \mathrm{min}) ; \mathrm{WAR}=$ Wistar audiogenic rats.

A

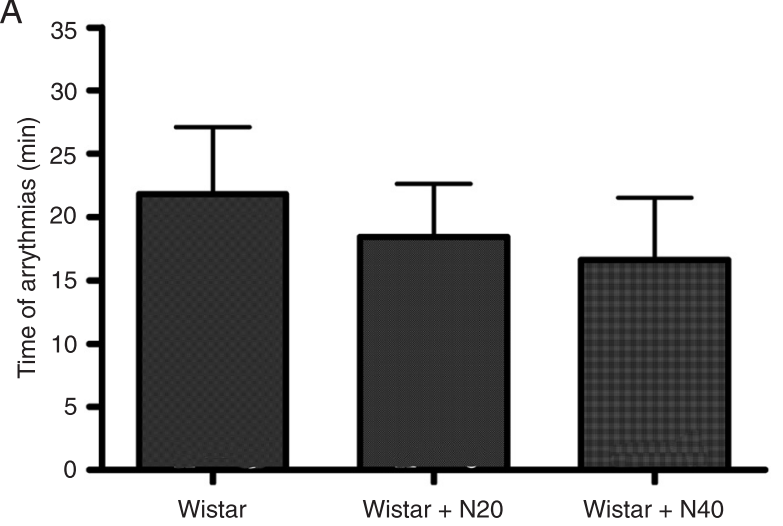

B

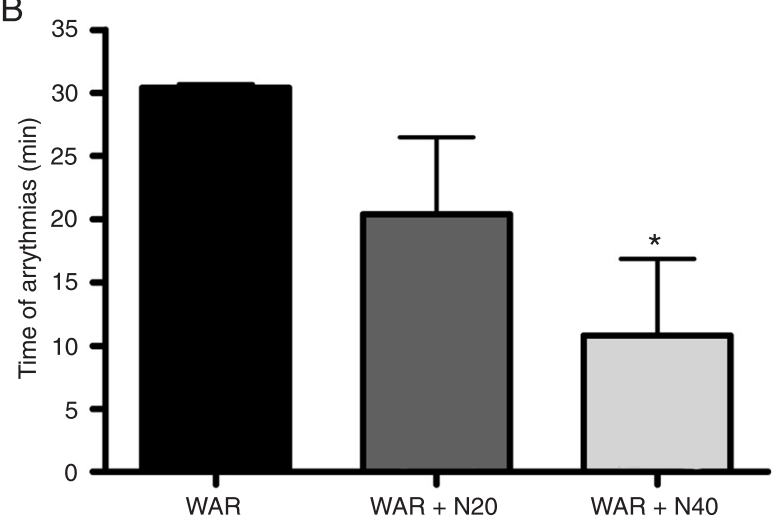

Figure 3. Effects of 20 and $40 \mathrm{mg} / \mathrm{kg}$ nifedipine (N20 and N40) on the duration of reperfusion arrhythmias in isolated hearts of $A$, Wistar rats and $B$, Wistar audiogenic rats (WAR). Data are reported as means \pm SEM for 6 rats per group. ${ }^{*} P<0.05$ compared to control (WAR) (one-way ANOVA followed by the Newman-Keuls post-test).

in WAR, but not in Wistar rats (Figure 3A). The arrhythmias in WAR were reversed to the normal sinus rhythm in 2 of the 6 animals treated with $20 \mathrm{mg} / \mathrm{kg}$ nifedipine and in 4 of the 6 animals treated with $40 \mathrm{mg} / \mathrm{kg}$ nifedipine. In Wistar rats, 4 of the 6 hearts returned to the normal sinus rhythm after both doses tested. None of the untreated WAR and Wistar rats returned to the normal sinus rhythm during the reperfusion period.

\section{Discussion}

The involvement of calcium channels in cellular excitability and the differences in the pharmacological and therapeutic actions of the calcium channel blockers prompted us to evaluate the effects of nifedipine on seizures and cardiac rhythm during the reperfusion of ischemic myocardium in WAR. We found that nifedipine has antiepileptic and antiarrhythmic effects in these animals. Indeed, some forms of epilepsy may be due to mutations in cell membrane $\mathrm{Ca}^{2+}$ channels (10) and changes in $\mathrm{Ca}^{2+}$ influx. These alterations probably are also involved in the initiation of VT and VF (8).

The anticonvulsant activity elicited by nifedipine observed in our study is in keeping with previous studies. Clinical data, as well as experimental studies have demonstrated that nifedipine reduces the severity of convulsions. For instance, this calcium blocker decreased the duration of the tonic hindlimb extensor phase in maximal electroshock seizures, increased the latent period and decreased the duration of clonic convulsions in pentylenetetrazole (PTZ)-treated animals (19). In chronic studies, nifedipine protected the animals against PTZ-induced kindling (20). Also, pretreatment with nifedipine reduced the duration of tonic extensor phase and the severity of convulsions in both electroshock and audiogenic seizures in albino mice (21). Gavranovic et al. (22) observed that anticonvulsant therapy with nifedipine resulted in a significant reduction in the incidence of seizures in 15 of the 18 patients evaluated. However, apparently the anticonvulsant effects of nifedipine in the audiogenic seizure model (DBA/2 mice) depend on 
the doses utilized. Usually, low doses of nifedipine have no effects on the behaviors of mice and do not protect against audiogenic seizures. On the other hand, a significant reduction of the incidence of the tonic and clonic phases was observed $45 \mathrm{~min}$ after high doses of nifedipine (15, 30 , and $45 \mathrm{mg} / \mathrm{kg}$ ) (23). In addition, Czuczwar et al. (24) observed that nifedipine $(20 \mathrm{mg} / \mathrm{kg}$ ) moderately inhibited PTZ-induced convulsions, while diltiazem (up to $20 \mathrm{mg} / \mathrm{kg}$ ) and verapamil (up to $20 \mathrm{mg} / \mathrm{kg}$ ) had no effect.

Calcium homeostasis plays a primary role in the induction of cardiac arrhythmias upon reperfusion (25). Alterations in $\mathrm{Ca}^{2+}$ influx are probably involved in the initiation of VT and VF after reperfusion. In fact, Brooks et al. (8) showed that VT/VF after myocardial reperfusion is immediately preceded by increases in the amplitude of the $\mathrm{Ca}^{2+}$ transient, thereby indicating that changes in the regulation of intracellular $\mathrm{Ca}^{2+}$ play a crucial role in initiating these arrhythmias. Importantly, it was observed that nifedipine decreases the vulnerability to VF in isolated rat hearts (26) and can inhibit ischemia-induced ventricular arrhythmias in conscious rats, but only at a high dose of $10 \mathrm{mg} / \mathrm{kg}$ (27).

The mechanisms by which the calcium channel antagonists induce protection against VF are complex, mainly due to the heterogeneity of the actions of these agents, i.e., i) reduction of heart rate, ii) preservation of high energy phosphate, iii) coronary artery vasodilation, iv) reduction in tissue cyclic AMP content, v) inhibition of transmembrane

\section{References}

1. Theodore WH, Spencer SS, Wiebe S, Langfitt JT, Ali A, Shafer PO, et al. Epilepsy in North America: a report prepared under the auspices of the global campaign against epilepsy, the International Bureau for Epilepsy, the International League Against Epilepsy, and the World Health Organization. Epilepsia 2006; 47: 1700-1722.

2. Ansakorpi $H$, Korpelainen JT, Suominen K, Tolonen U, Myllyla VV, Isojarvi JI. Interictal cardiovascular autonomic responses in patients with temporal lobe epilepsy. Epilepsia 2000; 41: 42-47.

3. Nei M, Ho RT, Sperling MR. EKG abnormalities during partial seizures in refractory epilepsy. Epilepsia 2000; 41: 542-548.

4. Cockerell OC, Johnson AL, Sander JW, Hart YM, Goodridge DM, Shorvon SD. Mortality from epilepsy: results from a prospective population-based study. Lancet 1994; 344: 918921.

5. Opherk C, Coromilas J, Hirsch LJ. Heart rate and EKG changes in 102 seizures: analysis of influencing factors. Epilepsy Res 2002; 52: 117-127.

6. Tigaran SPC, Dalager-Pedersen S, Baandrup U, Dam M, Vesterby-Charles A. Sudden unexpected death in epilepsy: is death by seizures a cardiac disease? Am J Forensic Med Pathol 2005; 26: 99-105.

7. Chen HI, Sun SC, Chai CY, Kau SL, Kou C. Encephalogenic cardiomyopathy after stimulation of the brain stem in monkeys. Am J Cardiol 1974; 33: 845-852. calcium influx, and vi) nonspecific effects. Thus, it is tempting to suggest that the antiarrhythmogenic effects induced by nifedipine in WAR observed in our study were, at least in part, due to the reduction in heart rate. The negative chronotropic effect is beneficial because a lower heart rate requires less oxygen consumption. Indeed, Laurent et al. (28) observed that coronary flow and cardiac oxygen consumption increase with higher heart rate. Interestingly, although nifedipine reduced the heart rate of isolated WAR and Wistar rat hearts, it decreased the duration of the arrhythmias only in WAR, indicating that the mechanisms underlying the reperfusion arrhythmias in WAR and Wistar rats are different.

The results of the present study indicated that nifedipine presents a mild anticonvulsant activity against audiogenic seizures and induces antiarrhythmogenic effects in WAR and Wistar rats. Thus, nifedipine may have an important therapeutic potential as an adjuvant non-sedative drug to treat epilepsy, especially in cases associated with cardiac rhythm abnormalities.

\section{Acknowledgments}

Research partially supported by CAPES, CNPq and Instituto Federal de Educação, Ciência e Tecnologia do Sudeste de Minas Gerais, Campus Barbacena.

8. Brooks WW, Conrad CH, Morgan JP. Reperfusion induced arrhythmias following ischaemia in intact rat heart: role of intracellular calcium. Cardiovasc Res 1995; 29: 536-542.

9. Harvey RD, Belevych AE. Muscarinic regulation of cardiac ion channels. Br J Pharmacol 2003; 139: 1074-1084.

10. Missiaen L, Robberecht W, van den Bosch L, Callewaert $\mathrm{G}$, Parys JB, Wuytack F, et al. Abnormal intracellular $\mathrm{Ca}^{2+}$ homeostasis and disease. Cell Calcium 2000; 28: 1-21.

11. Pal S, Limbrick DD Jr, Rafiq A, DeLorenzo RJ. Induction of spontaneous recurrent epileptiform discharges causes long-term changes in intracellular calcium homeostatic mechanisms. Cell Calcium 2000; 28: 181-193.

12. Garcia-Cairasco N, Wakamatsu H, Oliveira JA, Gomes EL, Del Bel EA, Mello LE. Neuroethological and morphological (Neo-Timm staining) correlates of limbic recruitment during the development of audiogenic kindling in seizure susceptible Wistar rats. Epilepsy Res 1996; 26: 177-192.

13. Magalhaes LH, Garcia-Cairasco N, Massensini AR, Doretto MC, Moraes MF. Evidence for augmented brainstem activated forebrain seizures in Wistar Audiogenic Rats subjected to transauricular electroshock. Neurosci Lett 2004; 369: 19-23.

14. Reis GM, Doretto MC, Duarte ID, Tatsuo MA. Do endogenous opioids and nitric oxide participate in the anticonvulsant action of dipyrone? Braz J Med Biol Res 2003; 36: 1263-1268.

15. Dias-Lopes C, Felicori L, Guimaraes G, Gomes ER, Roman- 
Campos D, Duarte H, et al. Cardiotoxic effects of Loxosceles intermedia spider venom and the recombinant venom toxin rLiD1. Toxicon 2010; 56: 1426-1435.

16. Almeida AP, Andrade AB, Ferreira AJ, Pires AC, Damasceno $D D$, Alves MN, et al. Antiarrhythmogenic effects of a neurotoxin from the spider Phoneutria nigriventer. Toxicon 2011; 57: 217-224.

17. Lubbe WF, Daries PS, Opie LH. Ventricular arrhythmias associated with coronary artery occlusion and reperfusion in the isolated perfused rat heart: a model for assessment of antifibrillatory action of antiarrhythmic agents. Cardiovasc Res 1978; 12: 212-220.

18. Bernauer W, Ernenputsch I. Antagonistic effects of alpha-adrenoceptor blocking agents on arrhythmias, enzyme release, and myocardial necrosis in isolated rat hearts with coronary occlusion and reperfusion. Naunyn Schmiedebergs Arch Pharmacol 1988; 338: 88-95.

19. Desai CK, Dikshit RK, Mansuri SM, Shah UH. Comparative evaluation of anticonvulsant activity of calcium channel blockers in experimental animals. Indian J Exp Biol 1995; 33: 931-934.

20. Khanna N, Bhalla S, Verma V, Sharma KK. Modulatory effects of nifedipine and nimodipine in experimental convulsions. Indian J Pharmacol 2000; 32: 347-352.

21. Sahadevan $P$, Rema MN. A comparative experimental study of the anticonvulsant effect of three calcium channel block- ers in albino mice. Indian J Pharmacol 2002; 34: 52-55.

22. Gavranovic M, Muller T, Sofic E, Bilalbegovic Z. Anticonvulsants combined with nifedipine for epilepsy in adults. Am J Psychiatry 1991; 148: 808-809.

23. De Sarro GB, Meldrum BS, Nistico G. Anticonvulsant effects of some calcium entry blockers in DBA/2 mice. Br J Pharmacol 1988; 93: 247-256.

24. Czuczwar SJ, Malek U, Kleinrok Z. Influence of calcium channel inhibitors upon the anticonvulsant efficacy of common antiepileptics against pentylenetetrazol-induced convulsions in mice. Neuropharmacology 1990; 29: 943-948.

25. Baxter GF, Yellon DM. Attenuation of reperfusion-induced ventricular fibrillation in the rat isolated hypertrophied heart by preischemic diltiazem treatment. Cardiovasc Drugs Ther 1993; 7: 225-231.

26. Thandroyen FT. Protective action of calcium channel antagonist agents against ventricular fibrillation in the isolated perfused rat heart. J Mol Cell Cardiol 1982; 14: 21-32.

27. Curtis MJ, Walker MJ. The mechanism of action of calcium antagonists on arrhythmias in early myocardial ischaemia: studies with nifedipine and DHM9. Br J Pharmacol 1988; 94: 1275-1286.

28. Laurent D, Bolene-Williams C, Williams FL, Katz LN. Effects of heart rate on coronary flow and cardiac oxygen consumption. Am J Physiol 1956; 185: 355-364. 